\title{
Revised Osmotic Pressure Estimation Program
}

\author{
Seung Jae Lim, Shin Hyo Bang, and Taeseon Yoon
}

\begin{abstract}
Recently, the Computer Technology advanced profoundly that the application has no limit. Equipped with programming, we wanted to make a program which is related to molecular science. While finding an appropriate adoption of computer programming to molecular science, we thought that estimating osmotic pressure might be the one. Previously, our recent research about Boiling Point Estimation Program [1] was highly recognized by international journal. Generally speaking, cellular membranes are semipermeable which allows osmosis to happen. To some extent, osmosis is explained by Van't Hoff Equation, which assumes solute's movement to be same as that of ideal gas. On this paper, however, we will use the modified version (to explain osmosis of real solution) of Van der Waals Equation, which is the corrected version of ideal gas equation.
\end{abstract}

Index Terms-Revised, osmotic pressure, van der waals equation, van't hoff equation.

\section{INTRODUCTION}

In this paper, we are going to suggest a computer related model which estimates osmotic pressure. Molecular Sciences and informatics seem an ill-assorted couple. Molecular Sciences is the scientific study of the structure of substances and of the way that they react with other substances. Informatics, by the way, is a study of the computer and statistics. We cannot discover chemical mechanisms by computer works. A standard, and traditional procedure for researching the field of molecular sciences would be doing experimental works. However, by analyzing the chemical patterns using informatics, we at least expect to demonstrate existing laws, or even gain new ones. The informatics could be used as a tool for molecular sciences.

The importance of computer in the field of Molecular Sciences is increasing; this year, three U.S. scientists won the Nobel chemistry prize on for pioneering work on computer programs. Similarly, we wanted to adopt a computer program into the world of molecules.

\section{EXPERIMENT OBJECT}

\section{A. Osmosis}

Osmosis is a type of diffusion. When there is permeable membrane (selectively accept substances to pass through) osmosis can occur. Cell membrane is well-known partially permeable membrane. Fig. 1 shows osmosis very well. In Fig $1, \mathrm{P}_{1 \mathrm{a}}$ is the high solute concentration solution and $\mathrm{P}_{2 \mathrm{a}}$ is the low solute concentration solution. At initial state, they remain

Manuscript received January 1, 2014; revised March 7, 2014.

The authors are with the Hankuk Academy of Foreign Studies, South Korea (e-mail: tonylim@gmail.com, whoami123461@gmail.com, tsyoon@hafs.hs.kr). steady with same height of water. At final state, however, water, which represents solvent of solution, rose up because the semi-permeable membrane between $\mathrm{P}_{1 \mathrm{a}}$ and $\mathrm{P}_{2 \mathrm{a}}$ caused osmosis that water from low solute concentration $\left(\mathrm{P}_{2 \mathrm{a}}\right)$ move to high solute concentration $\left(\mathrm{P}_{1 \mathrm{a}}\right)$. If the cell is submerged in saltwater, water molecules move out; if it is submerged in freshwater, however, water molecules move in; this is called osmosis. The selective cell membrane makes only necessary materials are let into the cell and wastes are left out.

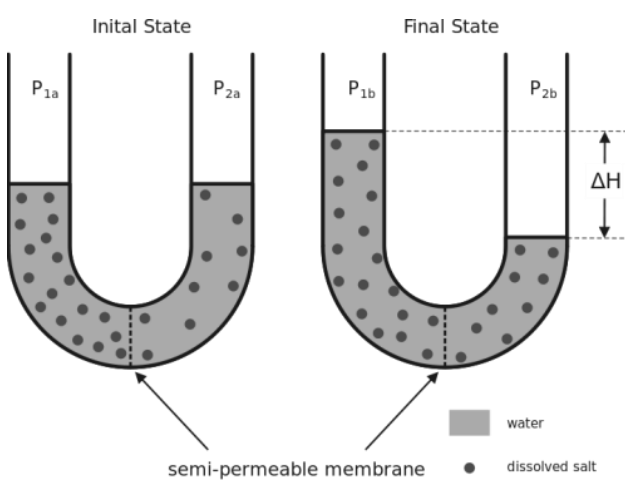

Fig. 1. Osmosis with Semi-permeable Membrane [2].

Osmosis can be explained using the concept of thermodynamic free energy: There are more free energy with low solute concentrated solution. Thus, its solvent molecules try to find a place of lower free energy in order to equalize free energy. Because the semi-permeable membrane selectively allows materials, only solvent molecules can pass through it. As a result, a net flow of water to the side with the higher solute concentrated solution. Let's assume that permeable membrane doesn't broke up. Then, this net flow will slow and finally stop at the equilibrium of the atmosphere pressure and osmotic pressure: this state is called dynamic equilibrium.

\section{B. Ideal Gas Equation and Its Revision}

$$
P V=n R T
$$

Equation (1) is Ideal Gas Equation [3]. The state of gas has always been a big interest for molecular scientists. And they drew the equation so called 'Ideal Gas equation.'

\begin{tabular}{ccc}
\multicolumn{2}{c}{ TABLE I: DIFFERENCE BETWEEN IDEAL GAS \& REAL GAS } \\
\hline Ideal Gas & Real Gas \\
Volume & $\mathrm{X}$ & $\mathrm{O}$ \\
$\begin{array}{c}\text { Interaction } \\
\text { Between } \\
\text { Molecules }\end{array}$ & $\mathrm{X}$ & $\mathrm{O}$
\end{tabular}

However, the ideal gas equation is literally available only 
for ideal gas. Since real gas has its own volume of each molecule and interaction between those, factors in the equation should be revised. The total volume of gas includes the volume of consisting molecules. Assuming the volume of the molecule as $\mathrm{b}$, the total volume taken by molecules is $n b$. So the revised factor of volume should be $V-n b$.

According to the ideal gas equation, 1-mol-gas filling 22.4L-container under 0 degrees Celsius should have a pressure of $1 \mathrm{~atm}$. However, the interaction between molecules results in a slightly decreased pressure. Interactions between molecules allow molecules to take less volume, which leads to the slight drop in pressure, which could be expressed as $P=\frac{n R T}{V}-k$. Basic physical rule says that the decreased distance between molecules results in the stronger interaction between those. If the volume increases, the distance between molecules will increase and the interaction will be weakened; the downsizing effect on pressure will decrease. Furthermore, if the number of molecules increases, which means the increased number of interactions, the dropping effect on pressure will increase. Van der Waals experimentally revised the pressure factor as $P-a \frac{n}{V^{2}}(a$ is a distinct value given to each gas).

$$
\left(P-a \frac{n}{V^{2}}\right)(V-n b)=n R T
$$

Equation (2) is Van der Waals Equation (Real Gas Equation). The ideal gas equation is quite reliable under high temperature and low pressure condition, because such conditions make the interaction between molecules to be minimized.

\section{State of Ideal Solution}

$$
\pi=i C R T,(i=1+(n-1) \alpha)
$$

Equation (3) is Van't Hoff Equation. The Van't Hoff equation is same with the ideal gas equation. The equation explains the state of an ideal solution. The basic hypothesis of this equation is that the ideal solute will act just like ideal gas molecule in the ideal solvent.

A solute sometimes ionizes if it is an electrolyte. So, the number of molecules should be revised. The revision factor $i$ depends on the number of ions the solute ionizes into. Also the degree of ionization affects $i$. Researchers found $i$ to be $1+(n-1) \alpha$.

\section{INDUCTION OF REVISED OSMOTIC PRESSURE EQUATION}

\section{A. Explanation}

While real gas has its revised version of equation that explains its state, so called 'Van der Waals Equation,' there is no existing estimation method for real solution. The Van't Hoff equation's hypothesis was that the solutes would act just like ideal gas molecules in ideal solution. Thus, it is thought that by adapting Van der Waals equation to estimate the

\begin{tabular}{|c|c|c|}
\hline Name & $\bar{A}\left(\mathrm{~L}^{2} \mathbf{a t m} / \mathrm{mol}^{2}\right)$ & b ( $(\mathbf{L} / \mathbf{m o l})$ \\
\hline Mercury & 8.2 & 0.01696 \\
\hline Neon & 0.2135 & 0.01709 \\
\hline Helium & 0.03457 & 0.0237 \\
\hline Hydrogen & 0.2476 & 0.02661 \\
\hline Nitric oxide & 1.358 & 0.02789 \\
\hline Water & 5.536 & 0.03049 \\
\hline Oxygen & 1.378 & 0.03183 \\
\hline Argon & 1.355 & 0.032 \\
\hline Ammonia & 4.225 & 0.0371 \\
\hline Nitrogen & 1.408 & 0.03913 \\
\hline Krypton & 2.349 & 0.03978 \\
\hline Carbon monoxide & 1.505 & 0.03985 \\
\hline Hydrogen chloride & 3.716 & 0.04081 \\
\hline Carbon dioxide & 3.64 & 0.04267 \\
\hline Methane & 2.283 & 0.04278 \\
\hline Hydrogen sulfide & 4.49 & 0.04287 \\
\hline Nitrous oxide & 3.832 & 0.04415 \\
\hline Nitrogen dioxide & 5.354 & 0.04424 \\
\hline Hydrogen bromide & 4.51 & 0.04431 \\
\hline Hydrogen selenide & 5.338 & 0.04637 \\
\hline Xenon & 4.25 & 0.05105 \\
\hline Phosphine & 4.692 & 0.05156 \\
\hline Acetylene & 4.516 & 0.0522 \\
\hline Fluoromethane & 4.692 & 0.05264 \\
\hline Silicon tetrafluoride & 4.251 & 0.05571 \\
\hline Chlorine & 6.579 & 0.05622 \\
\hline Sulfur dioxide & 6.803 & 0.05636 \\
\hline Silane & 4.377 & 0.05786 \\
\hline Ethane & 5.562 & 0.0638 \\
\hline Chloromethane & 7.57 & 0.06483 \\
\hline Methanol & 9.649 & 0.06702 \\
\hline Cyanogen & 7.769 & 0.06901 \\
\hline Dimethyl ether & 8.18 & 0.07246 \\
\hline Carbon disulfide & 11.77 & 0.07685 \\
\hline Ethanethiol & 11.39 & 0.08098 \\
\hline Ethanol & 12.18 & 0.08407 \\
\hline Ethylamine & 10.74 & 0.08409 \\
\hline Propane & 8.779 & 0.08445 \\
\hline Chloroethane & 11.05 & 0.08651 \\
\hline Dimethyl sulfide & 13.04 & 0.09213 \\
\hline Freon & 10.78 & 0.0998 \\
\hline Acetic acid & 17.71 & 0.1065 \\
\hline Acetone & 16.02 & 0.1124 \\
\hline Benzene & 18.24 & 0.1154 \\
\hline Acetonitrile & 17.81 & 0.1168 \\
\hline Diethyl sulfide & 19 & 0.1214 \\
\hline Butane & 14.66 & 0.1226 \\
\hline Acetic anhydride & 20.158 & 0.1263 \\
\hline Carbon tetrachloride & 19.7483 & 0.1281 \\
\hline Fluorobenzene & 20.19 & 0.1286 \\
\hline Diethyl ether & 17.61 & 0.1344 \\
\hline Ethyl acetate & 20.72 & 0.1412 \\
\hline Cyclohexane & 23.11 & 0.1424 \\
\hline Chlorobenzene & 25.77 & 0.1453 \\
\hline Pentane & 19.26 & 0.146 \\
\hline Toluene & 24.38 & 0.1463 \\
\hline Germanium tetrachloride & 22.9 & 0.1485 \\
\hline Bromobenzene & 28.94 & 0.1539 \\
\hline Tin tetrachloride & 27.27 & 0.1642 \\
\hline Iodobenzene & 33.52 & 0.1656 \\
\hline Hexane & 24.71 & 0.1735 \\
\hline
\end{tabular}
osmotic pressure of real solutions.

\section{B. Induction}

According to Van't Hoff Equation, osmotic pressure is 
described as multiple of Van't Hoff's factor (i), molar concentration of solute $(C)$, gas constant $(R)$ and absolute temperature $(T)$.

$$
\pi=i C R T
$$

Equation (4) which is a Van't Hoff Equation, concentration of solute $(C)$ is same as mol of solute per volume of solution $\left(\frac{n_{s}}{v}, n_{s}\right.$ : mole of solute, $V$ : volume of solution).

$$
\pi V=i n_{s} R T
$$

By adapting (4), (5) is induced. According to Van't Hoff equation, osmotic pressure in solution and ideal gas' pressure are known to be the same. In other words, $\mathrm{P}$, which represents pressure of ideal gas according to ideal gas equation, and $\pi$, which represents osmotic pressure are same. So, Van der Waals equation can be used to correct and revise Van't Hoff equation to be more appropriate for estimating real solution's osmotic pressure. But, there are a few things to be corrected before adapting it. $V$, which is the volume of solution replaced with $V-i n_{s} b$, has difference with Van der Waals equation's modified volume $(V-n b)$, because in solution, factor $i$ exists, which depends on whether solute is electrolyte or not. In ideal gas, it should be considered with gas molecules' own volume. However, in solution, it should be considered with increased volume effect due to ionization if it is electrolyte. So, factor $i$ is added to describe increased mol of solute. Similarly, $\pi$, which is the pressure of solute (same as gas), has difference with Van der Waals equation's revised pressure $\left(P-a \frac{n^{2}}{V^{2}}\right)$. Factor $i$ should be added contingently considering whether the solute is electrolyte or not.

$$
\left(\pi-a\left(\frac{\left(i_{s}\right)^{2}}{V^{2}}\right)\left(V-i n_{s} b\right)=i n_{s} R T\right.
$$

Using these facts, (6) which is revised Van't Hoff equation with Van der Waals equation, subsequently induced after (5).

$$
\pi_{r}=\frac{\{1+(n-1) \alpha\} n_{s} R T}{V-\{1+(n-1) \alpha\} n_{s} b}+a \frac{\left[\{1+(n-1) \alpha\} n_{s}\right]^{2}}{V^{2}}
$$

Lastly, by organizing equation and changing factor $i$ with specific equation $(i=1+(n-1) \alpha)$, (7) which is revised osmotic pressure equation (Lim's Equation) induced. Additionally, specific equation of factor $i, n$ represents for the number of ionized ion per one chemical species and $\alpha$ represents for degree of ionization.

\section{PROgRAMming AND APPLICATION}

\section{A. Source Code}

1) $P H P[5]$ if $(\$ s e c 1==" E l e c t r o l y t e ")$

\$numbers $=(((1+(\$ g 8-1) * \$ g 7) * \$ g 5 * 0.082 * \$ g 2) /((\$ g 1-(1$ $+\$ g 8-1) * \$ g 7) * \$ g 5 * \$ g 4))+(\$ g 3 *(((1+(\$ g 8-1) * \$ g 7) * \$ g 5) *(($ $1+(\$ g 8-1) * \$ g 7) * \$ g 5)) /(\$ g 1 * \$ g 1))$;

else

\$numbers $=((1 * \$ g 5 * 0.082 * \$ g 2) /((\$ g 1-1) * \$ g 5 * \$ g 4))+($ $\$ g 3 *((1 * \$ g 5) *(1 * \$ g 5)) /(\$ g 1 * \$ g 1))$

\section{2) $H T M L[6]$}

$\langle\mathrm{p}>$ Volume (V) :\&nbsp; $<$ font $\quad$ color="black" $><$ input type $=$ text name $=\mathrm{g} 1$ size $=4>\langle/$ font $>\mathrm{L}</ \mathrm{p}\rangle$

$\langle\mathrm{p}>$ Temperature $(\mathrm{T}) \quad:<$ font $\quad$ color="black" $\rangle\langle$ input type $=$ text name $=\mathrm{g} 2$ size $=4>\langle/$ font $\rangle \mathrm{K}</ \mathrm{p}\rangle$

$\langle$ p $>$ a :\&nbsp; $<$ font color="black" $><$ input type $=$ text name $=\mathrm{g} 3 \quad$ size $=4\rangle\langle/$ font $>\quad$ L2atm $/ \mathrm{mol} 2$ \&nbsp;\&nbsp;\&nbsp; $</ \mathrm{p}>$

$<\mathrm{p}>\mathrm{b} \quad: \&$ nbsp; $<$ font $\quad$ color $="$ black" $><$ input type $=$ text name $=$ g 4 size $=4>\langle/$ font $>\mathrm{L} / \mathrm{mol}</ \mathrm{p}\rangle$

$\langle$ p $>$ Mole of Solute(ns) : $<$ font color="black" $\rangle\langle$ input type $=$ text name $=\mathrm{g} 5$ size $=" 12 ">\langle/$ font $>$ mol $</ \mathrm{p}\rangle$

$<\mathrm{p}>\mathrm{R}=0.082 \mathrm{~atm} . \mathrm{L} / \mathrm{mol} . \mathrm{k}</ \mathrm{p}>$

$<\mathrm{p}>$ Degree of Ionization (alpha) : $<$ font color="black" $><$ input type=text name $=\mathrm{g} 7$

size $=4\rangle\langle/$ font $\rangle\langle/ \mathrm{p}\rangle$

$\langle\mathrm{p}\rangle$ Number of Ions (n) : $<$ font color="black" $><$ input type $=$ text name $=\mathrm{g} 8$ size $=4\rangle\langle/$ font $\rangle\langle/ \mathrm{p}\rangle$

The program is made with php language. The code shown above is the most essential part of the entire source code. The required variations in Revised Van't Hoff Equation are named $\mathrm{gN}$. If the user selects the solute as 'electrolyte,' the shown program implements. The internet address for this program is http://125.247.90.14/ osmotic/.

Revised Osmotic Pressure Estimation Program

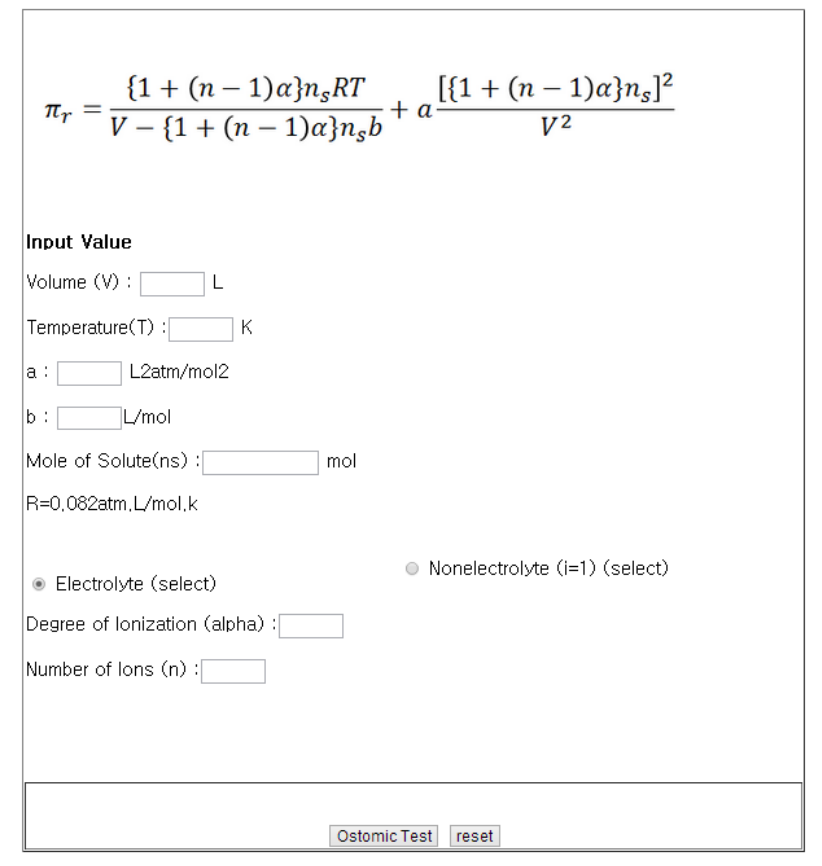

\section{EXPERIMENTS}

\section{A. Real Osmotic Pressure}

The solution used in the experiment was made by adding 
$5.945 \mathrm{~g} \mathrm{NaCl}$ (approximately $0.1 \mathrm{~mol}$ ) into $1.315 \mathrm{~L}$ of water. The solution was extracted into twenty $100 \mu \mathrm{L}$ samples using micro pipet. These 20 samples' osmotic pressure was measured by Osmomat Auto (HWASHIN Instrument co.). The average osmotic pressure of solution was 3.49atm.

\section{B. Program Based Osmotic Pressure}

According to the revised osmotic pressure estimation program, the osmotic pressure should be approximately 3.48atm. On the other hand, the osmotic pressure calculated by Van't Hoff equation was 3.46atm. The observational error of using Van't Hoff equation was 0.03atm and using revised osmotic pressure equation was 0.01atm. Thus, revised osmotic pressure equation significantly fits with real state solution even more than Van't Hoff equation.

\section{CONCLUSION}

\section{A. Results}

This research gained a formula which efficiently accounts for the osmotic pressure of real solutions. Furthermore, building a computer related program shows the potential of informatics that could be applied to chemistry

\section{B. Expectations}

There exists a revised equation for the state of gas, but none for solutions. Inspired by Van der Waals equation, authors revised osmotic pressure equation and made an estimation program. The result of experiment was successful which means that revised osmotic pressure equation fits well in real state.

\section{REFERENCES}

[1] S. H. Bang, S. J. Lim, and T. Yoon, "Aromatic compounds supplementing joback method," IJCEA vol. 5, March, 2014.

[2] Osmosis. (2014). [Online]. Available: http://wikipedia.com
[3] S. S. Zumdahl, Chemistry, $8^{\text {th }}$ edition, ch. 5.3, pp. 290-292, 2007.

[4] R. C. Weast, Handbook of Chemistry and Physics, 53th edition, Cleveland: Chemical Rubber Co., 1972.

[5] R. Nixon, Learning PHP, MySQL, JavaScript \& CSS, 2nd edition, pp. 95-141, August 2012

[6] D. Brian, Beginning Webgl for Html5, pp. 24-65, 2012.

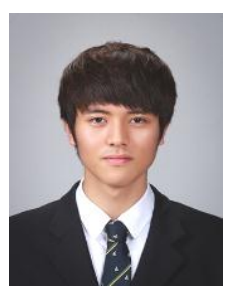

Seung Jae Lim was born in 1996 . He is currenty a student in science major of Hankuk Academy of Foreign Studies, Korea. He is mostly interested in Biology and has been studying pattern analysis and computer programming and its application to chemistry.

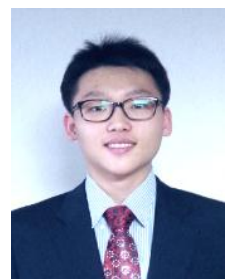

Shin Hyo Bang was born in 1997. He is currenty a student in science major of Hankuk Academy of Foreign Studies, Korea. He is mostly interested in energy resources and has been studying pattern analysis and computer programming and its application to chemistry.

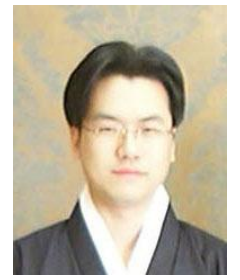

Taeseon Yoon was born in Seoul, Korea, in 1972. He received the $\mathrm{Ph}$.D. degree in computer education from the Korea University, Seoul, Korea, in 2003.

From 1998 to 2003, he was with EJB analyst and SCJP. From 2003 to 2004, he joined the Department of Computer Education, University of Korea, as a Lecturer and Ansan University, as an adjunct professor. Since December 2004, he has been with the Hankuk Academy of Foreign Studies, where he was a computer science and statistics teacher. He was the recipient of the Best Teacher Award of the Science Conference, Gyeonggi-do, Korea, 2013. 